\title{
The Glycolytic Enzyme PFKFB3 Is Involved in Estrogen-Mediated Angiogenesis via GPER1回
}

\author{
Annalisa Trenti, Serena Tedesco, Carlotta Boscaro, Nicola Ferri, Andrea Cignarella, \\ Lucia Trevisi, and Chiara Bolego
}

\author{
Department of Pharmaceutical and Pharmacological Sciences (A.T., S.T., Ca.B., N.F., L.T., Ch.B) and Department of Medicine \\ (A.C.), University of Padova, Padova, Italy
}

Received October 6, 2016; accepted March 22, 2017

\begin{abstract}
The endogenous estrogen $17 \beta$-estradiol (E2) is a key factor in promoting endothelial healing and angiogenesis. Recently, proangiogenic signals including vascular endothelial growth factor and others have been shown to converge in endothelial cell metabolism. Because inhibition of the glycolytic enzyme activator phosphofructokinase-2/fructose-2,6-bisphosphatase 3 (PFKFB3) reduces pathologic angiogenesis and estrogen receptor (ER) signaling stimulates glucose uptake and glycolysis by inducing PFKFB3 in breast cancer, we hypothesized that E2 triggers angiogenesis in endothelial cells via rapid ER signaling that requires PFKFB3 as a downstream effector. We report that treatment with the selective $G$ protein-coupled estrogen receptor (GPER1) agonist G-1 $\left(10^{-10}\right.$ to $\left.10^{-7} \mathrm{M}\right)$ mimicked the chemotactic and proangiogenic effect of E2 as measured in a number of short-term angiogenesis assays in human umbilical
\end{abstract}

vein endothelial cells (HUVECs); in addition, E2 treatment upregulated PFKFB3 expression in a time- and concentrationdependent manner. Such an effect peaked at 3 hours and was also induced by $\mathrm{G}-1$ and abolished by pretreatment with the GPER1 antagonist G-15 or GPER1 siRNA, consistent with engagement of membrane ER. Experiments with the PFKFB3 inhibitor 3-(3-pyridinyl)-1-(4-pyridinyl)-2-propen-1-one showed that PFKFB3 activity was required for estrogen-mediated HUVEC migration via GPER1. In conclusion, E2-induced angiogenesis was mediated at least in part by the membrane GPER1 and required upregulation of the glycolytic activator PFKFB3 in HUVECs. These findings unravel a previously unrecognized mechanism of estrogen-dependent endocrine-metabolic crosstalk in HUVECs and may have implications in angiogenesis occurring in ischemic or hypoxic tissues.

\section{Introduction}

The effects of female hormones, in particular the most abundant endogenous estrogen $17 \beta$-estradiol (E2), go beyond the well-established targets in reproductive organs and placenta. Estrogen exerts a protective role in the cardiovascular system by interacting with multiple cell types in the vessel wall including immune cells (Abu-Taha et al., 2009; Bolego et al., 2013) as well as resident smooth muscle (Geraldes et al., 2002; Maggi et al., 2003) and endothelial cells (ECs), the latter representing a major target of estrogen action (Morales et al., 1995; Holm et al., 1999; Rubanyi et al., 2002). In particular, E2 contributes to endothelial-mediated vasodilation by enhancing nitric oxide production (Bolego et al., 2010), promotes endothelial repair in the case of arterial injury (such as occurring in angioplasty procedures), and also fosters endothelial progenitor cell mobilization (Fadini et al.,

This work was supported by the University of Padova [Grant CPDA144389 to Ch.B., and institutional funding to A.C., L.T. and Ch.B.]

https://doi.org/10.1124/jpet.116.238212.

S This article has supplemental material available at jpet.aspetjournals.org.
2008; Toutain et al., 2009). Thus, available evidence points to E2 as being a key factor in promoting endothelial healing, as well as angiogenesis (Iwakura et al., 2006; Arnal et al., 2010).

In adult organisms, angiogenesis is virtually absent under normal conditions, except in the female reproductive tract, supporting a relevant role for sex steroids in the context of neovascularization processes (Reynolds et al., 1992; Losordo and Isner, 2001). This also applies to the setting of cardio- and cerebrovascular diseases, where a protective role of $\mathrm{E} 2$ in ameliorating ischemic damage has been demonstrated in models of ischemia-reperfusion injury (Fadini et al., 2008; Favre et al., 2010; Murata et al., 2013). Conversely, pathologic estrogen-dependent capillary growth is associated with conditions such as hemoangiomas (Conter and Longmire, 1988), endometriosis (Laschke and Menger, 2012), and breast cancer growth, which mainly correlates with nuclear estrogen receptor (ER) expression (Horak et al., 1992; Haran et al., 1994).

Estrogen effects are mediated by $\mathrm{ER} \alpha$ and $\mathrm{ER} \beta$, classic nuclear hormone receptors acting as transcription factors. Recently, a membrane-located ER belonging to the G proteincoupled receptor superfamily dubbed G protein-coupled estrogen receptor 1 (GPER1) has been discovered. This receptor is

ABBREVIATIONS: EC, endothelial cell; ECGF, endothelial cell growth factor; ER, estrogen receptor; E2, 17 $\beta$-estradiol; FBS, fetal bovine serum;

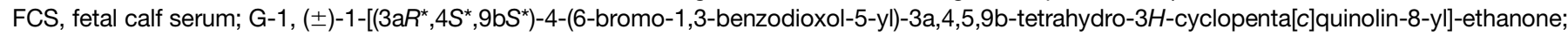
G-15, $\left(3 \mathrm{a} S^{\star}, 4 R^{\star}, 9 \mathrm{~b} R^{\star}\right)$-4-(6-bromo-1,3-benzodioxol-5-yl)-3a,4,5,9b-3H-cyclopenta[c]quinolone; GPER1, G protein-coupled estrogen receptor 1; HUVEC, human umbilical vein endothelial cell; PFKFB3, phosphofructokinase-2/fructose-2,6-bisphosphatase 3; 3PO, 3-(3-pyridinyl)-1-(4-pyridinyl)-2propen-1-one; MTT, 3-[4,5 dimethylthiazol-2-yl]-2,5 diphenyltetrazolium bromide. 
expressed in ECs, and mediates nongenomic rapid effects including calcium influx or kinase activation that are involved, among others, in the regulation of vascular tone (Prossnitz and Arterburn, 2015). Of note, long-term activation of GPER1 by selective pharmacological agents does not appear to induce uterotrophic effects (Meyer et al., 2014). ER $\alpha$ has been shown to mediate beneficial cardiovascular effects of E2 (Pare et al., 2002; Billon-Galés et al., 2009; Bolego et al., 2010; Favre et al., 2010), but it is also involved in pathologic cell proliferation (Harris et al., 2002). The proangiogenic effects of E2 have been mainly ascribed to ER $\alpha$ activation (Sanchez et al., 2011); accordingly, angiogenesis is impaired in ER $\alpha$ knockout mice (Johns et al., 1996). However, the possible contribution of the membrane GPER1 to such responses remains to be determined.

The mechanisms downstream ER activation involved in E2-mediated angiogenesis include increased production of proangiogenic factors and changes in the expression of adhesion molecules, as well as direct effects on EC proliferation and migration (Morales et al., 1995; Losordo and Isner, 2001; Geraldes et al., 2002; Arnal et al., 2010). An emerging regulatory mechanism is suggested by the observation that angiogenic signaling pathways converge in metabolism (Treps et al., 2016). Accordingly, it has been recently reported that pathologic angiogenesis can be inhibited by blocking the glycolytic enzyme activator phosphofructokinase-2/fructose2,6-bisphosphatase 3 (PFKFB3) (Schoors et al., 2014). The PFKFB3 product fructose-2,6-bisphosphate is the allosteric activator of the key glycolytic enzyme phosphofructokinase 1, and PFKFB3 represents the most abundant PFKFB isoenzyme in ECs (De Bock et al., 2013), which largely rely on glycolysis for ATP generation (Culic et al., 1997). Because PFKFB3 plays a role in nuclear signaling and its product increases the expression and activity of cyclin-dependent kinase-1 (Yalcin et al., 2009), PFKFB3 represents a novel pharmacological strategy for targeting angiogenesis and tumor cell growth/migration.

While E2 effects on several aspects of cell metabolism are well characterized (Mauvais-Jarvis et al., 2013; Della Torre et al., 2016), one report found that ER signaling stimulates glucose uptake and glycolysis by inducing PFKFB3 expression and activity in a breast cancer cell line (Imbert-Fernandez et al., 2014). However, it is still unknown if PFKFB3 is a molecular target of E2 in nontumor cell types such as ECs. To further explore the mechanisms underlying the proangiogenic effect of estrogen, we set out to assess the following: 1) whether the glycolytic activator PFKFB3 plays a role in E2-mediated angiogenesis and 2) whether GPER1 is involved in this process.

\section{Materials and Methods}

Cell Culture. Human umbilical vein ECs (HUVECs) were isolated from normal-term umbilical cords as previously published (Bolego et al., 2006). Briefly, cells were grown in medium M199 (Invitrogen, San Giuliano Milanese, Italy) supplemented with $15 \%$ fetal calf serum (FCS) (Invitrogen), gentamicin (40 $\mu \mathrm{g} / \mathrm{ml}$, Invitrogen), EC growth factor (ECGF) $(100 \mu \mathrm{g} / \mathrm{ml})$ and heparin (100 UI/ml, Sigma-Aldrich, Saint Louis, MO), at $37^{\circ} \mathrm{C}$ in a humidified $5 \% \mathrm{CO}_{2}$, atmosphere. HUVECs were identified by their morphology and detection of CD31related antigen, and used for experiments from passages 2-6. For Western blotting experiments, cells were switched to phenol-red-free M199 supplemented with the same reagents as the standard HUVEC culture medium 72 hours before each assay. The experiments were performed with phenol-free M199 supplemented with 5\% FCS, gentamicin $(40 \mu \mathrm{g} / \mathrm{ml})$, ECGF $(100 \mu \mathrm{g} / \mathrm{ml})$, and heparin $(100 \mathrm{UI} / \mathrm{ml})$.

Drugs and Chemicals. The following compounds were used in the experiments: E2 (Sigma-Aldrich); ( \pm )-1-[(3a $\left.R^{*}, 4 S^{*}, 9 \mathrm{~b} S^{*}\right)-4-(6-$ bromo-1,3-benzodioxol-5-yl)-3a,4,5,9b-tetrahydro-3H-cyclopenta[c] quinolin-8-yl]-ethanone (G-1) (Tocris Bioscience, Bristol, United Kingdom); ( $\left.3 \mathrm{a} S^{*}, 4 R^{*}, 9 \mathrm{~b} R^{*}\right)$-4-(6-bromo-1,3-benzodioxol-5-yl)$3 \mathrm{a}, 4,5,9 \mathrm{~b}-3 H$-cyclopenta[c]quinoline (G-15) (Tocris Bioscience); and 3-(3-pyridinyl)-1-(4-pyridinyl)-2-propen-1-one (3PO) (Merck Millipore, Darmstadt, Germany). Inhibitors were added 30 minutes before the stimulus.

MTT Assay. HUVECs $\left(2 \times 10^{4}\right.$ cells/well $)$ were seeded in 96-well culture plates and incubated in complete culture medium. The next day, the medium was replaced with a fresh one containing the test agents and cells were incubated for 24 hours. Four hours before the incubation ended, $10 \mu \mathrm{l}$ stock solution of 3-[4,5 dimethylthiazol-2-yl]2,5 diphenyltetrazolium bromide (MTT, $5 \mathrm{mg} / \mathrm{ml}$ in phosphatebuffered saline) was added to each well. At the end of the incubation, the medium was removed and formazan crystals were dissolved in $100 \mu \mathrm{l}$ dimethylsulfoxide. MTT reduction was quantified by measuring light absorbance with a Wallac Victor2 plate reader (PerkinElmer Life and Analytical Sciences, Waltham, MA) at 570-630 nm. Background absorbance values from control wells (cell-free media) were subtracted. Cell viability is expressed as the raw optical density value.

Wound-Healing Assay. HUVECs $\left(1 \times 10^{5}\right.$ cells $)$ were seeded in complete culture medium on $1 \%$ gelatin-coated 24 -well culture plates and allowed to reach confluence. One scratch was made and the medium was replaced with fresh complete medium containing test compounds. Three images for each sample were captured at $40 \times$ under an Eclipse Ti phase contrast inverted microscope (Nikon, Tokyo) equipped with a digital camera at different time points: immediately after the scratch was made (time 0 ) and after 6 hours (end of incubation time). The wound area of each image was measured using the ImageJ version 1.47 software (National Institutes of Health, Bethesda, MD), and the average wound area of three images was determined for each sample. Quantitative analysis of cell migration was performed as the percentage of area change using the following formula: $\%$ change $=($ average wound area at time 0 hours $)-($ average wound area at time 6 hours)/(average wound area at time 0 hours) $\times$ 100. Values are expressed as percentage of change from control cells.

Chemotaxis Assay. Chemotaxis experiments were performed in a 48-well modified Boyden chamber (Neuro Probe, Gaithersburg, MD) using $8-\mu \mathrm{m}$ nucleopore polyvinylpyrrolidine-free polycarbonate filters coated with $10 \mu \mathrm{g} / \mathrm{ml}$ collagen. Lower chambers were filled with phenol-free M199 supplemented with $1 \%$ fetal bovine serum (FBS) and $100 \mathrm{U} / \mathrm{ml}$ heparin in the presence or absence of $10 \mathrm{ng} / \mathrm{ml}$ vascular endothelial growth factor or G-1 $\left(10^{-9}\right.$ to $\left.10^{-7} \mathrm{M}\right)$, whereas upper chambers were filled with $50 \mu \mathrm{l}$ cell suspension $\left(1.6 \times 10^{5}\right.$ cells in phenol-free M199 supplemented with $1 \% \mathrm{FBS}$ and $100 \mathrm{U} / \mathrm{ml}$ heparin). After 6-hour incubation at $37^{\circ} \mathrm{C}$, nonmigrating cells on the upper filter surface were removed by scraping. The cells that had migrated to the lower side of the filter were stained with Diff-Quick stain (VWR Scientific Products, Bridgeport, NJ), and densitometric analysis was performed using the ImageJ version 1.47 software (National Institutes of Health). Each experiment was performed in sextuplicate and the results are shown as the mean values of five independent assays.

Capillary-Like Tube Formation Assay. HUVECs $\left(2 \times 10^{4}\right.$ cells/well) were plated onto a thin layer $(140 \mu \mathrm{l})$ of a basement membrane matrix (Matrigel; Becton Dickinson, Waltham, MA) in 48-well plates, and incubated at $37^{\circ} \mathrm{C}$ for 4 hours in cell culture medium in the presence or absence of test compounds as indicated in Results. Two images per well were captured at $40 \times$ under an Eclipse Ti phase contrast inverted microscope (Nikon) equipped with a digital camera. Images were analyzed using Angiogenesis Analyzer, a plugin developed for the ImageJ software (Carpentier et al., 2012). The data on the topological parameters (number of junctions, master segment meshes, and total mesh area) of the capillary-like network were 
analyzed in each well. Junctions are measured as pixels with three neighbors and master segments define segments delimited by two junctions (Guidolin et al., 2004). Data are expressed as either absolute values or percentage of control.

Western Blot Analysis. HUVECs $\left(3 \times 10^{5} / 35-\mathrm{mm}\right.$ dish $)$ were seeded in complete culture medium in $1 \%$ gelatin-coated dishes. Upon confluence the medium was replaced. Cells were treated as indicated in Results and lysed with $100 \mu \mathrm{l}$ lysis buffer (phosphate-buffered saline supplemented with $1.2 \%$ Triton X-100, cOmplete Protease Inhibitor Cocktail (Roche Diagnostics, Mannheim, Germany), NaF $2.5 \mathrm{mM}, \mathrm{Na}_{4} \mathrm{P}_{2} \mathrm{O}_{7} 2 \mathrm{mM}$ (Sigma-Aldrich), Na orthovanadate $4 \mathrm{mM}$, and phenylmethanesulfonylfluoride $1 \mathrm{mM}$ ). After centrifugation at $10,000 \mathrm{~g}$ for 15 minutes, supernatants were collected for SDS-PAGE and Western blotting. Protein quantification was performed by the BCA Assay (Sigma-Aldrich). Proteins $(40-60 \mu \mathrm{g})$ were separated on SDS-PAGE and transferred onto Amersham Hybond-P polyvinylidene difluoride membranes. Membranes were then blocked and probed using the following rabbit primary antibodies: anti-PFKFB3 (GE Healthcare Europe, Milan, Italy); anti-GPER1 (Abcam, Cambridge, United Kingdom); and anti-glyceraldehyde-3-phosphate dehydrogenase (Santa Cruz, Dallas, TX). After washing, membranes were incubated with appropriate secondary horseradish peroxidase-conjugated antibodies (Vector Laboratories, Burlingame, CA) at 1:2500 dilution. Bands were detected by chemiluminescence using the LiteAblot Turbo (Euroclone, Pero, Italy). Images were acquired with the VersaDoc 4000 Imaging System (Bio-Rad, Hercules, CA). Densitometric analysis of bands was performed with ImageJ version 1.47 software (National Institutes of Health). Results are expressed as percentage of controls.

RNA Interference. HUVECs were seeded at a density of $2 \times 10^{5}$ cells per well into 35 -mm dishes in complete medium. After 24 hours, they were transfected with siLentFect (Bio-Rad) and $20 \mathrm{nM}$ siRNA (ON-TARGETplus Human GPER11 (2852) SMARTpool siRNA; Dharmacon, Lafayette, CO) per well in complete culture medium with $15 \%$ FBS. A scrambled siRNA without sequence homology to any known human gene served as the negative control. After 72 hours, fresh complete medium with 15\% FBS was added, and pharmacological treatments were started as indicated for migration, Matrigel, and immunoblotting assays. GPER1 protein levels were measured after 72-hour transfection to assess knockdown efficiency.

Statistical Analysis. All experiments were performed in at least three independent replicates. The results are presented as mean values, with error bars representing the S.E.M. of the average value. Statistical analysis was performed using GraphPad Prism 5.02 (GraphPad Software Inc., La Jolla, CA). Student's $t$ test was used to compare the mean values of two independent groups, whereas oneway analysis of variance followed by Dunnett's or Bonferroni's post hoc tests was used for multiple comparisons. A $P$ value of $<0.05$ was considered statistically significant.

\section{Results}

The Proangiogenic Effect of Estrogen Involves the Membrane GPER1. Although the proangiogenic effect of E2 has already been described (Morales et al., 1995), the role of the membrane receptor GPER1 in mediating this effect has not been assessed. For this purpose, we used a variety of in vitro experimental approaches mimicking the major steps of the angiogenic process (Rubanyi et al., 2002; Simons et al., 2015). We first performed a chemotaxis assay to assess HUVEC migration in response to the selective GPER1 agonist G-1 at early time points (4 hours). As shown in Fig. 1A, the number of migrating cells significantly increased in response to increasing concentrations of G-1 $\left(10^{-10}\right.$ to $\left.10^{-7} \mathrm{M}\right)$. At the highest concentration, the effect of G-1 on migration was comparable to that of the positive control vascular endothelial growth factor $(10 \mathrm{ng} / \mathrm{ml})$. Throughout the concentration range of this assay, the selective GPER1 agonist did not significantly affect HUVEC viability over the 24-hour incubation (Fig. 1B).

To assess the effect of G-1 on collective HUVEC migration, we used a wound-healing migration assay. It was seen that similarly to the equimolar E2 concentration, G-1 $\left(10^{-7} \mathrm{M}\right)$ promoted wound closure (Fig. 2, A and B). Pretreatment of E2stimulated cells with the selective GPER1 antagonist G-15 $\left(10^{-6} \mathrm{M}\right)$ appeared to counteract this effect, although in a statistically nonsignificant manner.

Finally, we analyzed the effect of G-1 on tubularization, the process of organizing HUVECs into capillary tube-like structures when cultured onto extracellular matrix proteins (Fig. 3A). As shown in Fig. 3B, treatment with $10^{-7}$ M G-1 increased specific parameters of capillary-like tube formation
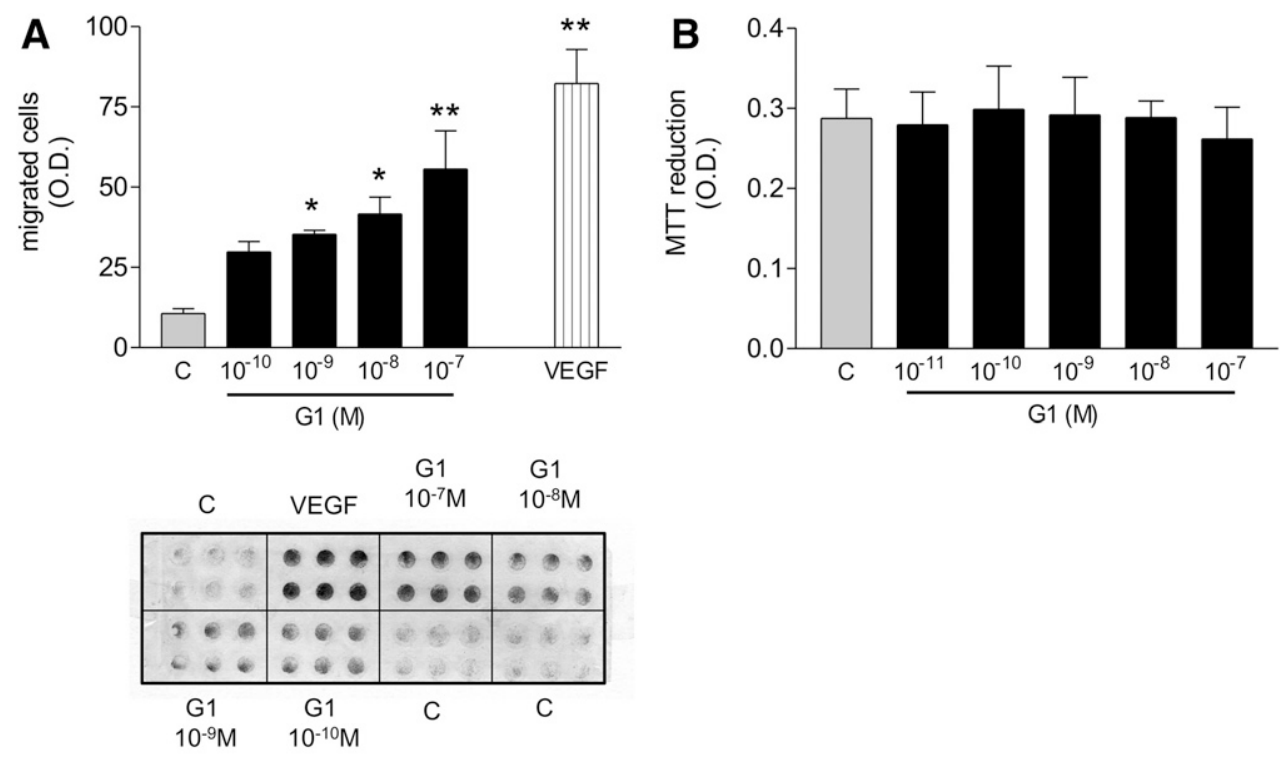

Scale bar: $-0.5 \mathrm{~cm}$
Fig. 1. Estrogen-mediated HUVEC migration involves the membrane receptor GPER1. (A) HUVEC migration in response to increasing concentrations of the selective GPER1 agonist G-1 $\left(10^{-7}\right.$ to $10^{-10} \mathrm{M}$ ) was measured in a microchemotaxis chamber after 6 hours. (Upper panel) Data are expressed as mean \pm S.E.M. of five independent experiments performed in sextuplicate (one-way analysis of variance, Dunnett's post hoc test: ${ }^{*} P<0.05 ; * * P<0.01$ versus control). (Lower panel) Representative images of migrated cells on the bottom of a filter membrane as detailed in Materials and Methods. Scale bar: $0.5 \mathrm{~cm}$. (B) HUVECs plated in 96-well plates $\left(10^{4}\right.$ cells/well $)$ were incubated in phenol red-free complete culture medium with 5\% FBS in the presence of G-1 $\left(10^{-11}\right.$ to $\left.10^{-7} \mathrm{M}\right)$ for 24 hours. Cell viability was measured by MTT assay. Data are expressed as mean \pm S.E.M. of three independent experiments performed in quadruplicate. 


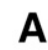

A
T0

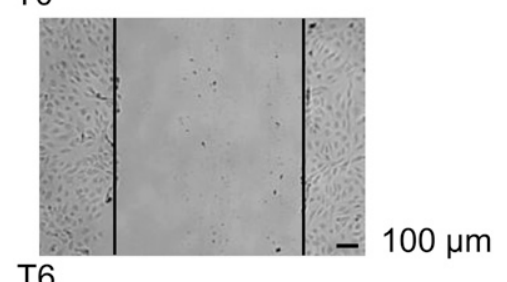

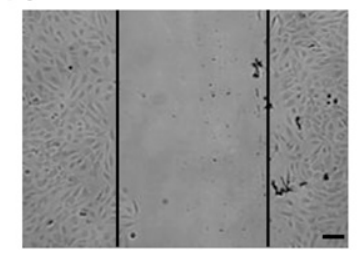

C

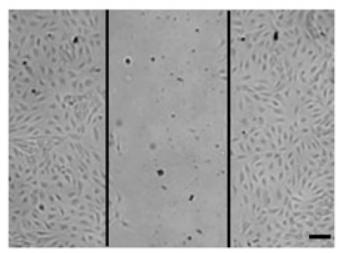

E2

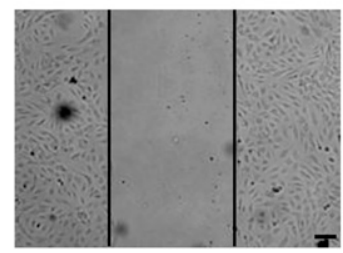

G1

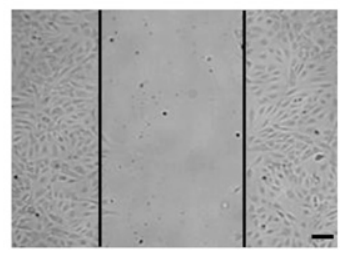

$\mathrm{E} 2+\mathrm{G} 15$

B

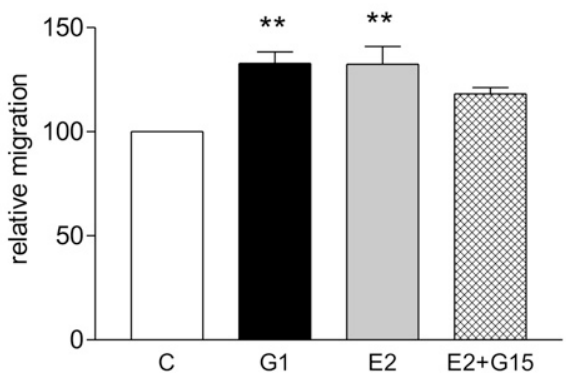

Fig. 2. E2 promotes wound healing through GPER1. HUVECs were seeded in 24 -well plates ( $10^{5}$ cells/well), wounded, and treated with G-1 or E2 (10 $\left.{ }^{-7} \mathrm{M}\right)$. The selective G-1 antagonist G-15 $\left(10^{-6} \mathrm{M}\right)$ was added 30 minutes before E2. (A) Representative image (scale bar: $\left.100 \mu \mathrm{m}\right)$; (B) Quantitative analysis of wound-healing experiments. Wound closure was calculated as described in Materials and Methods. Bars show the mean \pm S.E.M. of four independent experiments. One-way analysis of variance, Bonferroni's post hoc test: $* * P<0.01$ versus control.

such as junction number, mesh area, mesh number, and master segment number of HUVECs seeded onto Matrigel and incubated in phenol red-free medium containing 5\% FCS and ECGF $(100 \mu \mathrm{g} / \mathrm{ml})$. The effect of the selective GPER1 agonist was similar to that induced by E2 and was antagonized by G-15 $\left(10^{-6} \mathrm{M}\right)$, further suggesting that the proangiogenic effect of estrogens was mediated, at least in part, by the membrane GPER1.

17ß-Estradiol Increases PFKFB3 Expression in ECs via GPER1. To assess a possible contribution of the glycolytic activator PFKFB3 to HUVEC migration in response to ER agonists, we first analyzed the effect of E2 on PFKFB3 expression. E2 enhanced PFKFB3 protein levels in a timedependent (1-24 hours) (Fig. 4A) and concentrationdependent $\left(10^{-9}\right.$ to $\left.10^{-7} \mathrm{M}\right)$ (Fig. 4B) manner. The increased expression of PFKFB3 in response to E2 peaked at 3 hours (Fig. 4A) and was also detectable at the lowest E2 concentration tested $\left(10^{-9} \mathrm{M}\right)$ (Fig. 4B). No changes in PFKFB3 mRNA levels were observed following E2 treatment (Supplemental Fig. 1). The selective GPER1 antagonist G-15 abolished the E2-mediated effect on PFKFB3 expression (Fig. 5A). We also performed experiments with the ER antagonist ICI 182,780, which failed to abolish the effect of E2 on PFKFB3 protein amount, and even turned out to behave as an agonist by enhancing PFKFB3 expression (Supplemental Fig. 2) in line with previous evidence (Thomas et al., 2005). Moreover, similarly to E2, treatment with the selective GPER1 agonist G-1 $\left(10^{-9}\right.$ to $\left.10^{-7} \mathrm{M}\right)$ induced a concentration-dependent increase in PFKFB3 levels (Fig. 5B), which reached statistical significance at the highest concentration tested, further supporting a role for GPER1 in ER signaling in ECs.

To provide additional evidence for the involvement of GPER1 in E2-mediated angiogenesis we performed additional experiments using a GPER1-specific siRNA. Treatment of HUVECs with GPER1 siRNA for 72 hours led to a significant reduction in the GPER1 protein amount compared with control (Fig. 6A). Consistent with a role for GPER1 in E2mediated angiogenesis, no significant changes in HUVEC migration in response to E2 were observed in GPER1 knockout in contrast to control HUVECs (Fig. 6B). Similarly, an impaired response in capillary-like network formation was observed in HUVECs treated with GPER1 siRNA with respect to scramble-treated cells (Fig. 6C). Finally, we demonstrated that E2 treatment failed to induce a significant increase in PFKFB3 level in GPER1 knockout cells (Fig. 6D).

PFKFB3 Is Required for Estrogen-Mediated EC Migration via GPER1. Given that both E2 and G-1 enhanced accumulation of PFKFB3, which is known to play a key role in the angiogenic process (Schoors et al., 2014), we tested the effect of E2 in HUVECs pretreated with the PFKFB3 inhibitor, 3PO $(40 \mu \mathrm{M})$. As shown in Fig. 7A, 3PO alone inhibited the migratory potential of ECs grown in the presence of $5 \% \mathrm{FCS}$ and ECGF (100 $\mu \mathrm{g} / \mathrm{ml})$, and abolished the woundclosure effect elicited by E2. In addition, treatment with 3PO for 24 hours did not affect MTT reduction (Fig. 7B), suggesting that under these experimental conditions and in this time 
A CTR

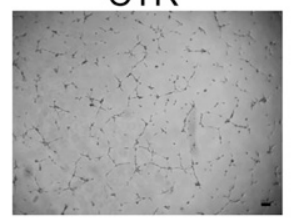

B
E2
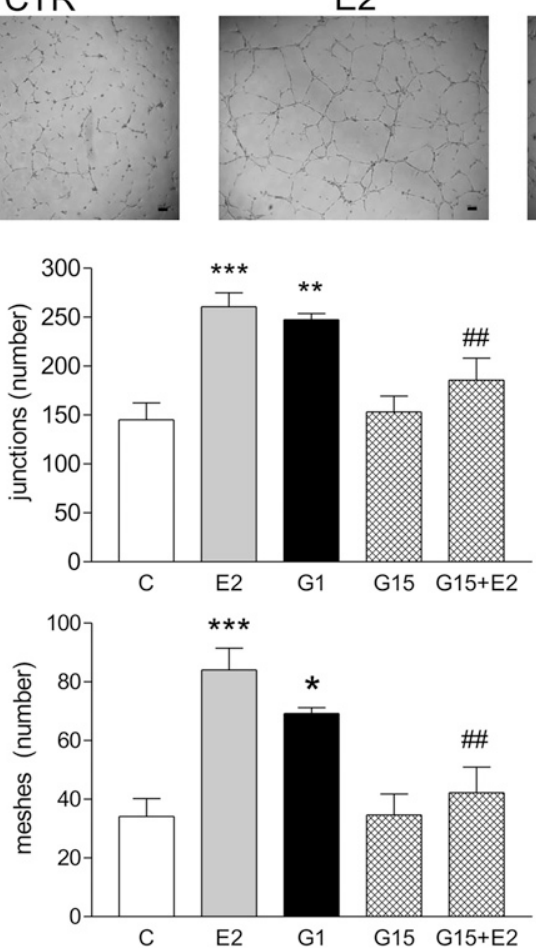

G1
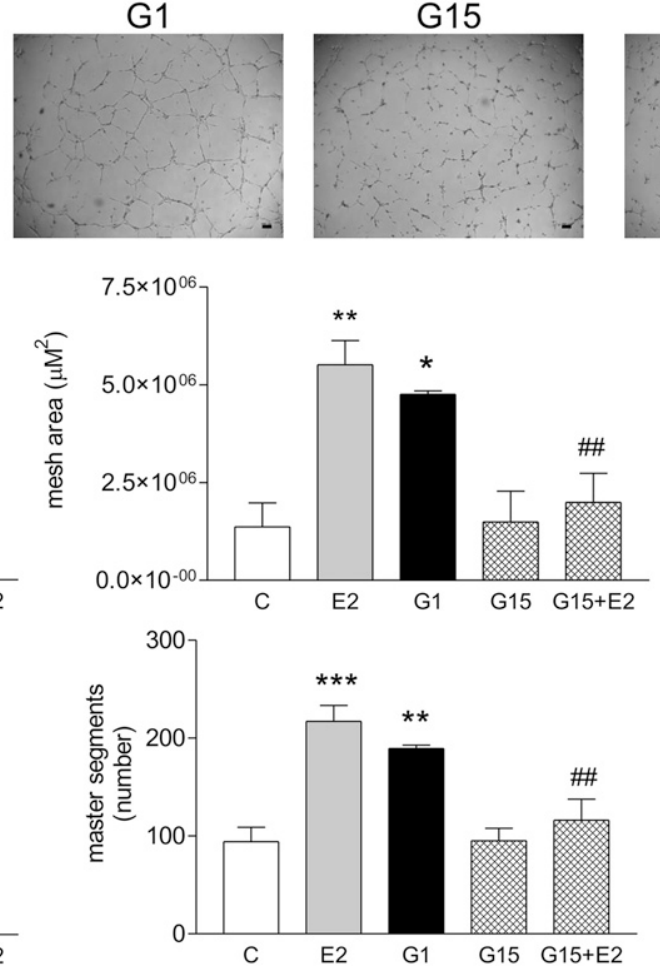

Fig. 3. The selective GPER1 agonist G-1 promotes the formation of tube-like structures, while the GPER1 antagonist G-15 counteracts E2-mediated effects. HUVECs $\left(2 \times 10^{4}\right.$ cells/well) were seeded onto 48 -well plates coated with Matrigel in phenol red-free complete culture medium with $5 \%$ FBS and treated with G-1 or E2 (both $10^{-7} \mathrm{M}$ ) in the presence or absence of G-15 $\left(10^{-6} \mathrm{M}\right)$. (A) Representative phase contrast microphotographs (scale bar: $100 \mu \mathrm{m}$ ); (B) Quantitative analysis of specific parameters of capillary tube formation after 4-hour incubation on Matrigel as determined using Angiogenesis Analyzer (ImageJ). Data are expressed as mean \pm S.E.M. of five independent experiments. One-way analysis of variance, Bonferroni's post hoc test: $* P<0.05 ; * * P<0.01 ; * * * P<0.001$ versus control; ${ }^{\# \#} P<0.01$ versus E2.

frame inhibition of glycolysis did not influence cell viability and/or proliferation. Furthermore, 3PO inhibited the ability of E2-challenged ECs to form capillary-like structures. As was similarly observed for $\mathrm{E} 2$, $3 \mathrm{PO}$ also abolished the proangiogenic potential of the selective GPER1 agonist G-1 (Fig. 8), thereby reinforcing the involvement of this membrane receptor in the formation of tube-like structures. To further support the consequences of PFKFB3 inhibition on the angiogenic process, we performed additional experiments using a selective PFKFB3 inhibitor, PFK15, at a concentration lower than that of $3 \mathrm{PO}$. The data showed that treatment with $1 \mu \mathrm{M}$ PFK15 counteracted ER ligand-mediated angiogenesis similar to 3PO (Supplemental Fig. 3A) without affecting HUVEC viability (Supplemental Fig. 3B).

\section{Discussion}

In the present study we provide evidence for the membrane GPER1 and the glycolytic activator PFKFB3 playing a role in estrogen-mediated angiogenesis, thereby highlighting for the first time such an estrogen-dependent endocrine-metabolic crosstalk in HUVECs. These data relay estrogen with glycolysis and energy production with angiogenesis, a critical step of tumor growth/metastasis.

Angiogenesis is a tightly regulated process comprising several sequential steps, which involve mediators produced by both normal tissues under physiologic conditions and in pathologic settings. Female reproductive organs (ovary, uterus, and placenta), well-recognized estrogen targets, exhibit periodic growth and regression, supporting a role of female hormones, in particular the most abundant endogenous estrogen E2, in physiologic angiogenesis (Reynolds et al., 1992). Moreover, several studies suggest a beneficial effect of female hormones in the regeneration of ischemic tissues, where estrogen-mediated angiogenesis may improve outcomes (Iwakura et al., 2006; Fadini et al., 2008). The proangiogenic effect of E2 has also been established in pathologic conditions characterized by a proinflammatory environment, including endometriosis and tumors of reproductive organs, where the proangiogenic effect is considered deleterious (Haran et al., 1994; Laschke and Menger, 2012). The opposite role of estrogen-mediated angiogenesis in cardiovascular disease as opposed to cancer is in line with the knowledge that antiangiogenic therapies are associated with deleterious cardiovascular effects (Daher and Yeh, 2008). In addition, E2 accelerates cutaneous wound healing, a process closely associated with angiogenesis (Hardman and Ashcroft, 2008), and protects against skin ischemia (Toutain et al., 2009).

The mechanisms responsible for the proangiogenic effect of E2 have been widely characterized, including an effect on endothelial cytoskeletal architecture via $\mathrm{ER} \alpha$ (Geraldes et al., 2002; Arnal et al., 2010; Sanchez et al., 2011). However, there are few and inconsistent data on the role of the membrane GPER1 (Holm et al., 2012; Prossnitz and Barton, 2014), a G protein-coupled ER expressed by a number of tissues including the vascular endothelium, where it mediates rapid hormone effects (Revankar et al., 2005). We here demonstrate 
A

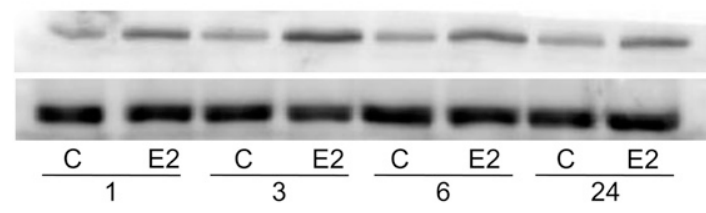

B
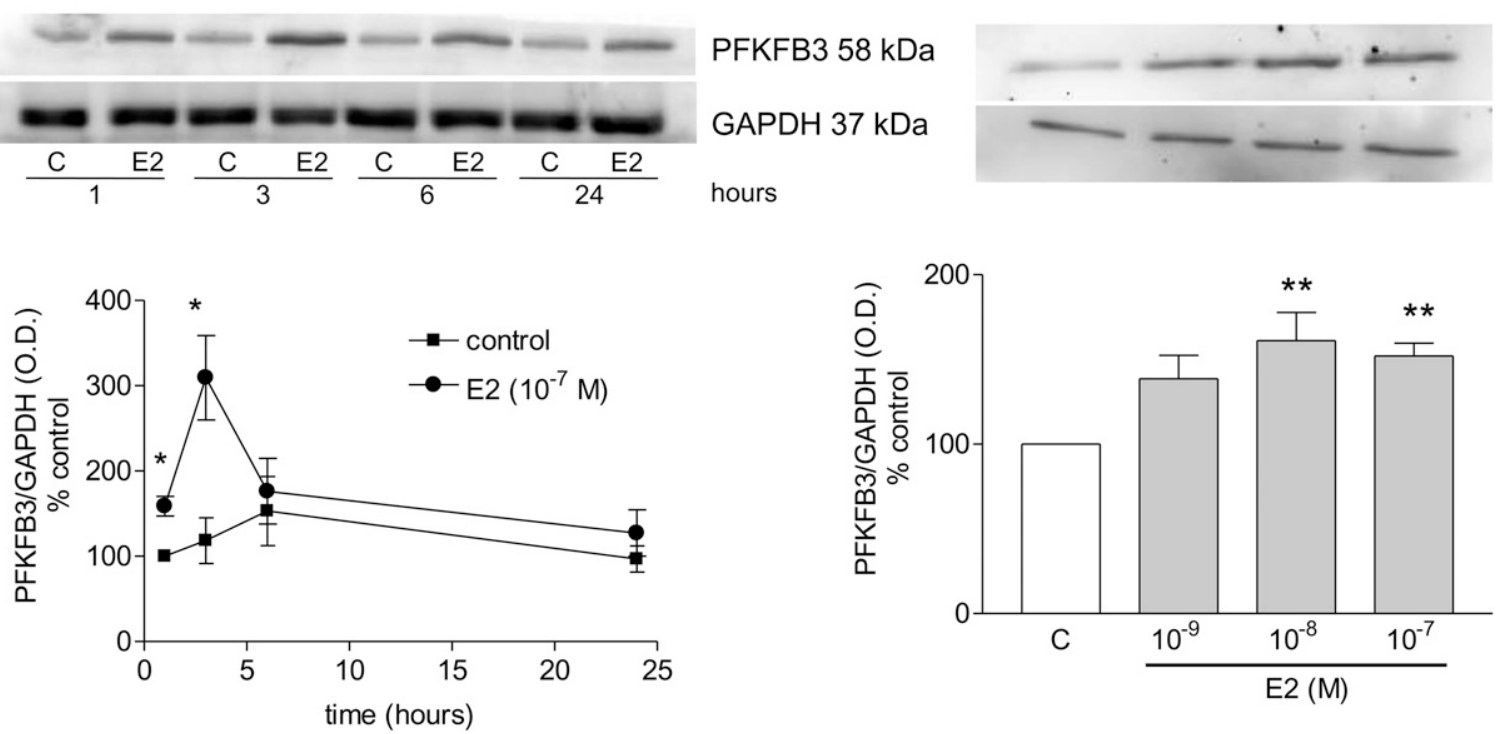

Fig. 4. E2 induces PFKFB3 expression in a time- and concentration-dependent manner. (A) HUVECs $\left(3 \times 10^{5} /\right.$ well) were grown in 35 -mm dishes, and after reaching confluence were treated with $10^{-7} \mathrm{M} \mathrm{E2}$ in phenol red-free complete medium with 5\% FBS for the time indicated. (Upper panel) Representative blots showing the expression of PFKFB3; glyceraldehyde-3-phosphate dehydrogenase (GAPDH) expression was used as a loading control. (Lower panel) Densitometric analysis of bands, normalized to GAPDH levels, expressed as percentage of control. Data are expressed as mean \pm S.E.M. of five independent experiments; $t$ test: $* P<0.05$ versus control. (B) HUVECs $\left(3 \times 10^{5} /\right.$ well) were grown in 3.5 -cm dishes, and after reaching confluence were treated with E2 $\left(10^{-9}\right.$ to $\left.10^{-7} \mathrm{M}\right)$ in phenol red-free complete medium with 5\% FBS for 3 hours. (Upper panel) Representative blots showing PFKFB3 detection; GAPDH expression was used as a loading control. (Lower panel) Densitometric analysis of bands, normalized to GAPDH levels, expressed as percentage of control. Data are expressed as mean \pm S.E.M. of five independent experiments. One-way analysis of variance, Dunnett's post-test: $* * P<0.01$ versus control.

that the selective GPER1 agonist G-1 induced a concentrationdependent increase in HUVEC migration, which was already detectable at concentrations in the low nanomolar range. More importantly, we found that G-1 promoted the morphologic differentiation of HUVECs into capillary-like structures, thus mimicking in vitro some of the steps involved in angiogenesis in vivo (Rubanyi et al., 2002). This effect was prevented by selective antagonists, further supporting a role for GPER1 in

A

B
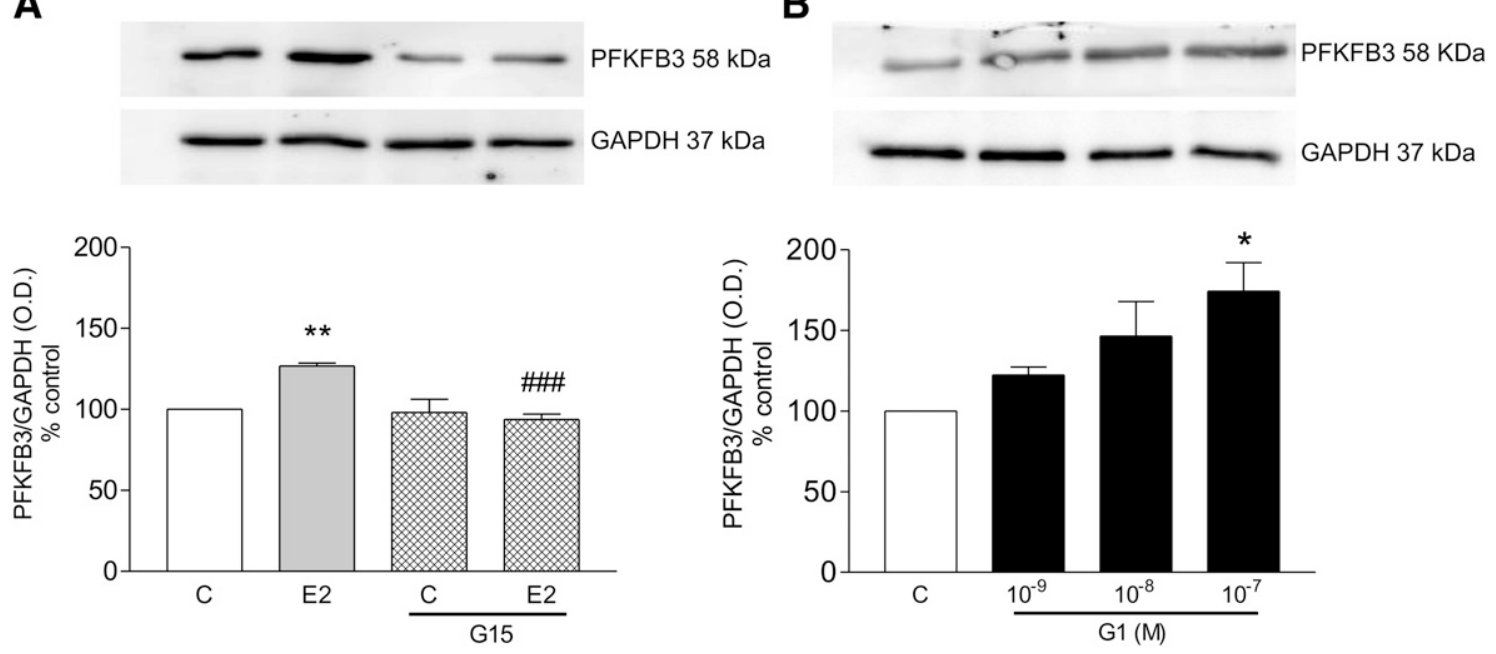

Fig. 5. The selective GPER1 agonist G-1 enhances the expression of PFKFB3 while the GPER1 antagonist G-15 blocks E2-mediated PFKFB3 expression. (A) HUVECs $\left(3 \times 10^{5} /\right.$ well) were grown in $35-\mathrm{mm}$ dishes, and upon confluence were treated with $10^{-7} \mathrm{M} \mathrm{E} 2 \mathrm{in}$ phenol red-free complete medium with 5\% FBS for 3 hours. The selective GPER1 antagonist G-15 $\left(10^{-6} \mathrm{M}\right)$ was added 30 minutes before E2. (Upper panel) Representative blots showing the expression of PFKFB3; glyceraldehyde-3-phosphate dehydrogenase (GAPDH) expression was used as a loading control. (Lower panel) Densitometric analysis of bands, normalized to GAPDH levels, expressed as percentage of control. Data are expressed as mean \pm S.E.M. of five independent experiments. One-way analysis of variance (ANOVA), Bonferroni's post-test: ${ }^{* *} P<0.01$ versus control; \#\#\# $P<0.001$ versus E2. (B) HUVECs $\left(3 \times 10^{5} /\right.$ well) were grown in 3.5-cm dishes, and after reaching confluence were treated with G-1 $\left(10^{-9}\right.$ to $\left.10^{-7} \mathrm{M}\right)$ in phenol red-free complete medium with 5\% FBS for 3 hours. (Upper panel) Representative blots showing PFKFB3 immunodetection; GAPDH was used as a loading control. (Lower panel) Densitometric analysis of bands, normalized to GAPDH, expressed as percentage of control. Data are expressed as mean \pm S.E.M. of three independent experiments. One-way ANOVA, Dunnett's post hoc test: $* P<0.05$ versus control. 


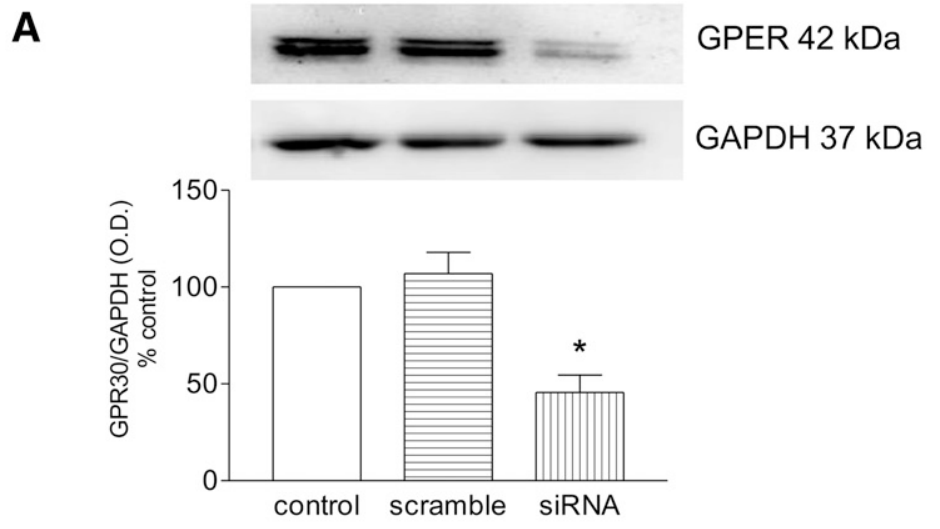

B
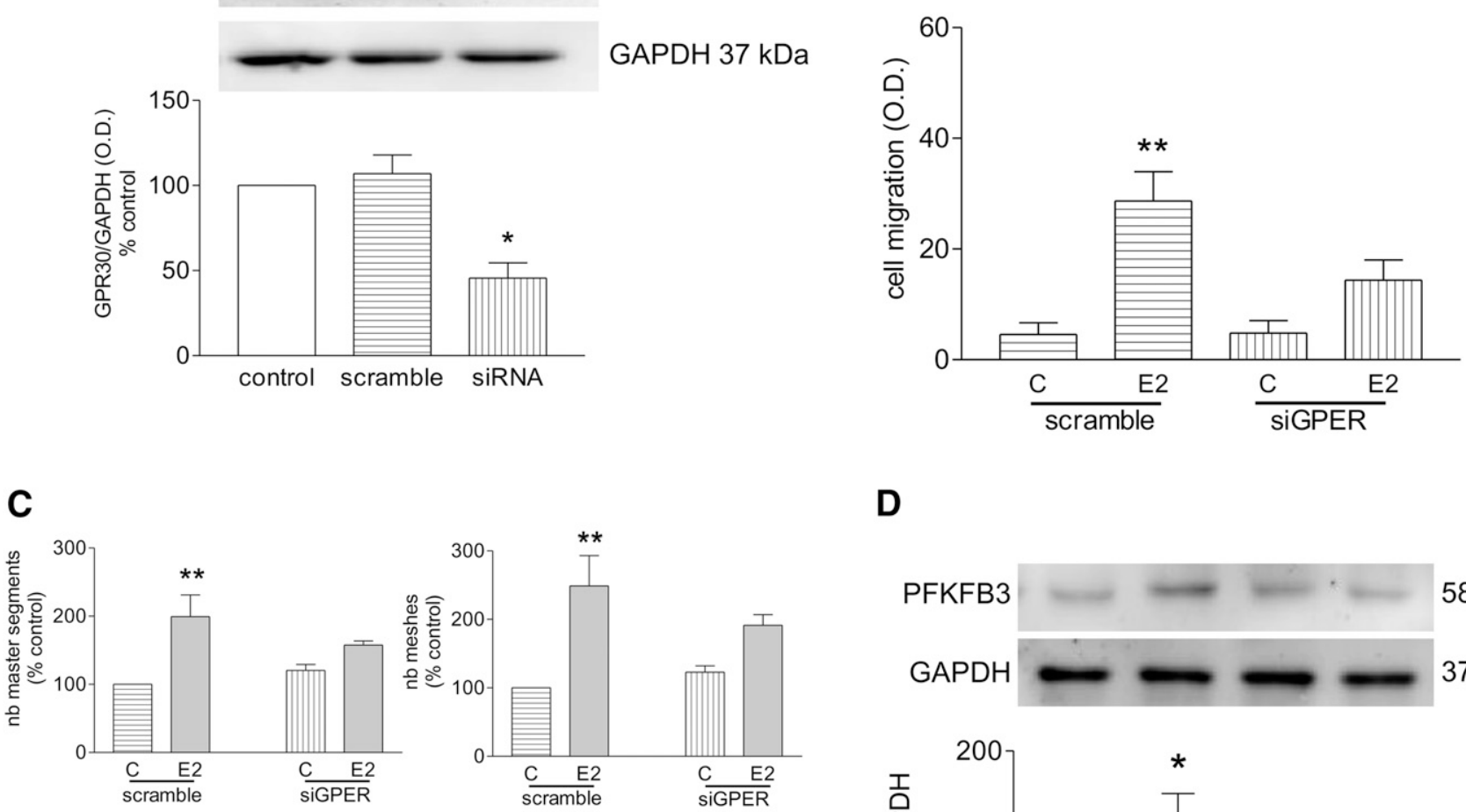

D
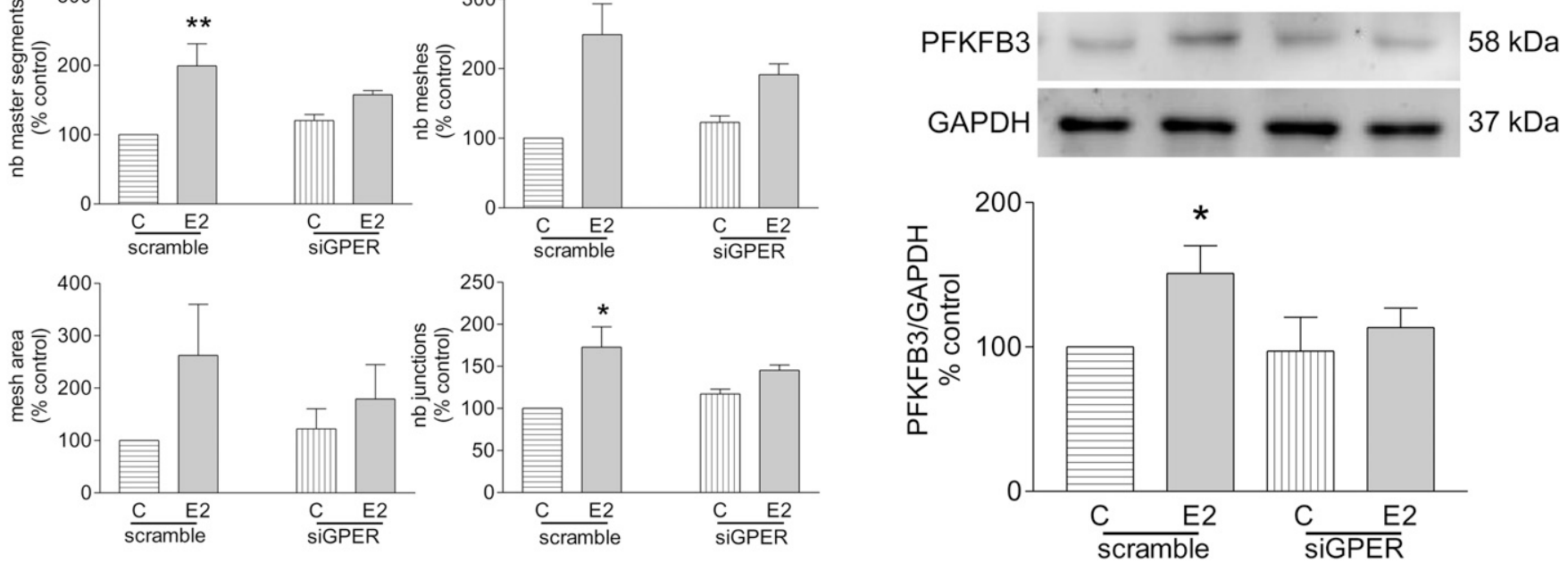

Fig. 6. Treatment with GPER1 siRNA reduces E2-mediated HUVEC migration, tube-like structure formation, and PFKFB3 expression. HUVECs $(2 \times$ $10 \%$ well) were seeded in $35-\mathrm{mm}$ dishes, and after 24 hours were transfected with siRNA for 72 hours. After transfection, fresh complete medium was added and pharmacological treatments were started as indicated. (A and D) Cell lysates were subjected to Western blotting as described in Fig. 5. (Upper panel) Representative blots showing the expression of GPER1 and PFKFB3, respectively; glyceraldehyde-3-phosphate dehydrogenase (GAPDH) was used as a loading control. (Lower panel) Densitometric analysis of bands, normalized to GAPDH levels, expressed as percentage of control. Data are expressed as mean \pm S.E.M. of three independent experiments. One-way analysis of variance (ANOVA), Dunnett's post hoc test: ${ }^{*} P<0.05$ versus control. (B) HUVEC migration in response to E2 $\left(10^{-7} \mathrm{M}\right)$ was measured in a microchemotaxis chamber as described in Fig. 1. Data are expressed as mean \pm S.E.M. of five independent experiments performed in sextuplicate. One-way ANOVA, Dunnett's post hoc test: $* * P<0.01$ versus control. (C) HUVECs $\left(2 \times 10^{4}\right.$ cells/well) were seeded onto Matrigel-coated 48-well plates in phenol red-free complete culture medium with $1 \%$ FBS containing E2 $\left(10^{-7} \mathrm{M}\right)$. Capillary tube formation on Matrigel was assessed after 4-hour incubation using Angiogenesis Analyzer (ImageJ) as described in Fig. 3. Data are expressed as mean \pm S.E.M. of three independent experiments. One-way ANOVA, Dunnett's post hoc test, ${ }^{*} P<0.05$ versus control.

E2-mediated angiogenesis. We also show that the selective GPER1 agonist did not affect EC viability/proliferation over 24 hours, consistent with the idea that previously described effects on cell migration and tubularization are independent of HUVEC proliferation. However it is possible that at later time points G-1 could enhance proliferation and/or inhibit HUVEC apoptosis, in line with studies using the endogenous ligand E2 (Morales et al., 1995; Spyridopoulos et al., 1997; Fadini et al., 2008).

Overall, our data point to GPER1 as a promising target in promoting angiogenesis associated with beneficial cardiovascular effects such as those observed in the setting of ischemic damage (Iwakura et al., 2006; Fadini et al., 2008). In fact, consistent with a major role in hypoxia-mediated signaling, GPER1 regulates the hypoxic-ischemic response in both the cardiovascular and central nervous system (Patel et al., 2010;
Murata et al., 2013; Lappano et al., 2016). Notably, pharmacological GPER1 activation does not appear to induce undesired effects on reproductive tissues such as the uterus (Meyer et al., 2014). In fact, no changes in uterine growth were detected in two GPER1 knockout mouse models (Otto et al., 2009; Windahl et al., 2009). Despite the lack of general agreement on the impact of GPER1 selective agonists in nonvascular tissues (Prossnitz and Barton, 2014), several studies conversely point to a predominant role for $\mathrm{ER} \alpha$ in estrogen and tamoxifen uterotrophic effects (Nasu et al., 2008; Bolego et al., 2010). Hence, pharmacological activation of GPER1 may be safer than estrogen-based therapeutic regimens in relation to the female genital tract.

Based on the knowledge that HUVECs resemble cancer cells in their preferential use of glycolysis (Verdegem et al., 2014) to generate most of their ATP for functional responses 
T0

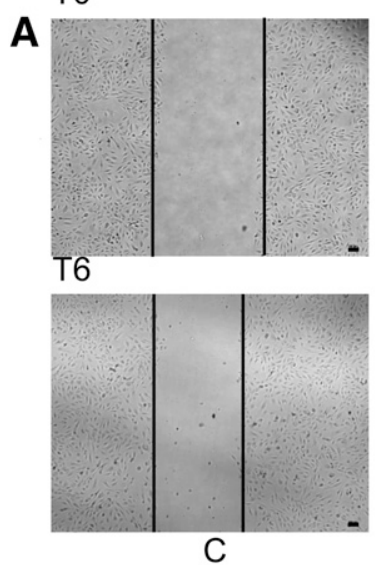

$100 \mu \mathrm{m}$

B

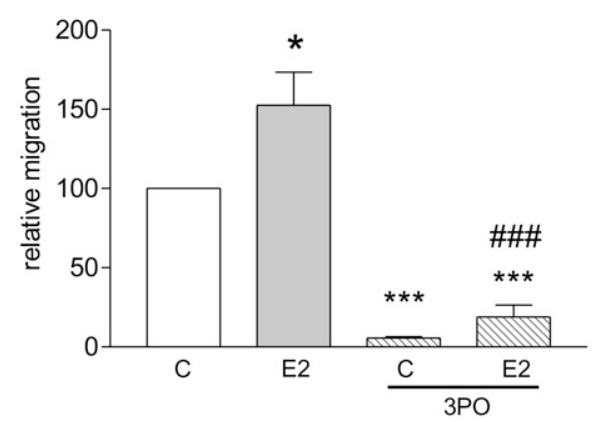

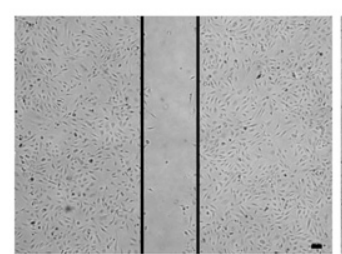

E2
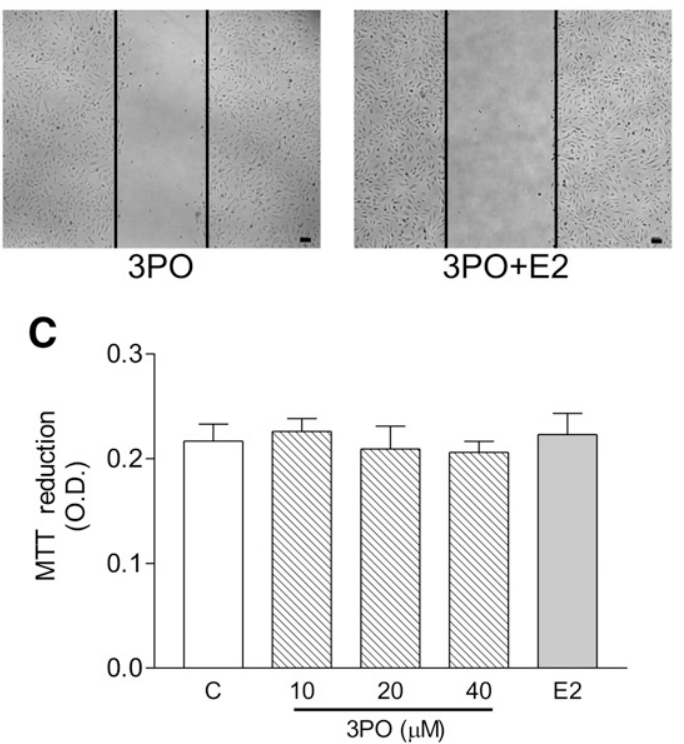

Fig. 7. The PFKFB3 inhibitor 3 PO inhibits E2-mediated collective HUVEC migration without affecting cell viability. HUVECs (10 5 cells/well) were plated in 24-well plates and the assay was performed in confluent cells as described in Materials and Methods. (A) Representative images of a woundhealing experiment after 6-hour incubation in phenol red-free complete culture medium with 5\% FBS. HUVECs were treated with $10^{-7} \mathrm{M}$ E2; $3 \mathrm{PO}$ $(40 \mu \mathrm{M})$ was added 30 minutes before E2 (T0: upon wounding; T6: 6-hour incubation, scale bar: $100 \mu \mathrm{m}$ ). (B) Quantitative analysis of wound closure as described in Materials and Methods. Data are expressed as mean \pm S.E.M. of five independent experiments. One-way analysis of variance, Bonferroni's post hoc test: $* P<0.05$; ${ }^{* * *} P<0.001$ versus control; ${ }^{\# \# \# ~} P<0.001$ versus E2. (C) HUVECs $\left(10^{4}\right.$ cells/well) were plated in 96-well plates and incubated in phenol red-free complete culture medium with 5\% FBS in the presence of 3PO $(10-40 \mu \mathrm{M})$ or E2 $\left(10^{-7} \mathrm{M}\right)$. Cell viability was measured by MTT assay. Data are the mean \pm S.E.M of three independent experiments performed in quadruplicate.

including angiogenesis, we focused on the glycolytic activator PFKFB3, a downstream effector of several proangiogenic growth factors including the vascular endothelial growth factor (Goveia et al., 2014), to further explore the mechanisms involved in E2-mediated angiogenesis via GPER1. Of note, PFKFB3 has a hypoxia inducible factor-responsive element in
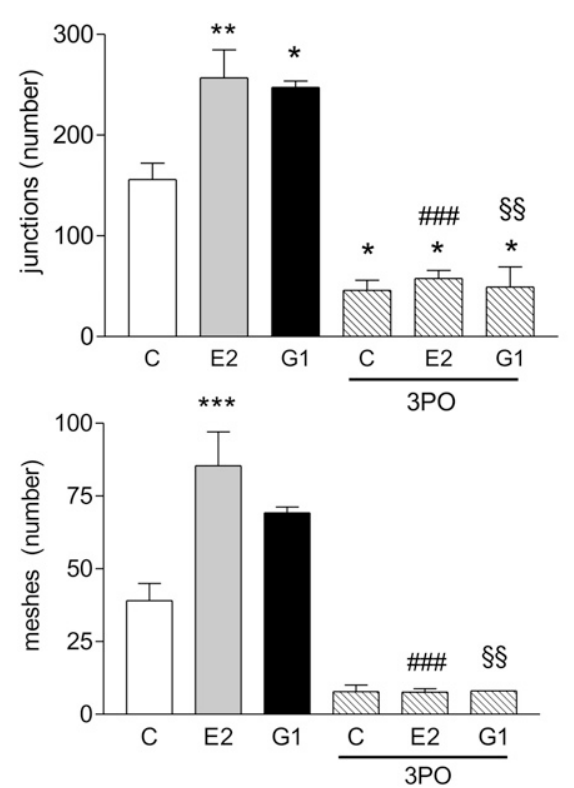
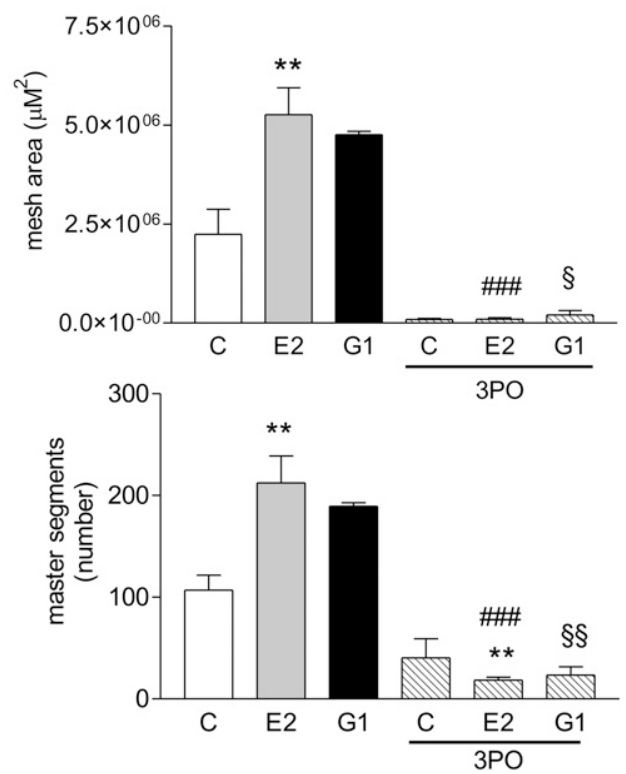

Fig. 8. The PFKFB3 inhibitor $3 \mathrm{PO}$ blocks the formation of tube-like structures induced by E2 via GPER1. HUVECs $\left(2 \times 10^{4}\right.$ cells/well $)$ were seeded onto Matrigel-coated 48-well plates in phenol red-free complete culture medium with $5 \%$ FBS containing E2 $\left(10^{-7} \mathrm{M}\right)$ or G-1 $\left(10^{-7} \mathrm{M}\right)$ in the presence or absence of $3 \mathrm{PO}(40 \mu \mathrm{M})$. Quantitative analysis of specific parameters of capillary tube formation after 4-hour incubation on Matrigel was performed using Angiogenesis Analyzer (ImageJ). Data are expressed as mean \pm S.E.M of five independent experiments. One-way analysis of variance, Bonferroni's post hoc test: $* P<0.05 ; * * P<0.01 ; * * * P<0.001$ versus control; \#\#\# $P<0.001$ versus E2; ${ }^{\circledR} P<0.05 ;{ }^{\S} P P<$ 0.01 versus $\mathrm{G}-1$. 
its promoter (Obach et al., 2004), and its expression is upregulated under hypoxic conditions such as those associated with ischemic tissue and cancer (CorderoEspinoza and Hagen, 2013; Xu et al., 2014; Tawakol et al., 2015). Therefore, it is not surprising that multiple proangiogenic factors rely on PFKFB3-mediated glycolysis for their effect. Pharmacological inhibition of PFKFB3 leads to partial reduction of glycolysis, which in turn negatively affects cell proliferation and migration in ECs. Therefore, PFKFB3 targeting represents a promising antiangiogenic strategy overcoming resistance and insufficient efficacy of classic antiangiogenic therapies (Schoors et al., 2014).

Recently, it has been demonstrated that E2 increases PFKFB3 expression in breast cancer cells and thereby sustains tumor growth (Imbert-Fernandez et al., 2014). Therefore, we hypothesized that the increased angiogenic response in E2-exposed HUVECs was mediated by PFKFB3. In line with this hypothesis, we demonstrated that: 1) E2 enhanced PFKFB3 expression in a time- and concentrationdependent manner; and 2) the selective PFKFB3 inhibitor $3 \mathrm{PO}$ abolished the wound-healing closure as well as the morphologic differentiation of E2-treated HUVECs to form capillary-like structures. Interestingly, the increase in PFKFB3 levels upon E2 treatment compared with control was already detectable after 1 hour and peaked after 3 hours, consistent with the activation of a membrane receptor. Such a rapid response was not due to $P F K F B 3$ transcriptional activation (Supplemental Fig. 1). It has been described that PFKFB3 expression can be regulated at post-translational levels by several mechanisms including mRNA or protein stability (Chesney et al., 1999; Riera et al., 2003; Almeida et al., 2010). We are currently investigating the mechanism by which estradiol increases PFKFB3 protein expression with out affecting gene transcription. However, since a role for $\mathrm{ER} \alpha$ and downstream intracellular kinases, including the focal adhesion kinase, has been suggested in angiogenesis (Sanchez et al., 2011; Gopal et al., 2012), and since E2 decreases miR206 and increases PFKFB3 expression in breast cancer cells through $\mathrm{ER} \alpha$ (Imbert-Fernandez et al., 2014; Ge et al., 2015), we cannot exclude receptor crosstalk and/or functional redundancy with ER $\alpha$ in HUVECs (Prossnitz and Barton, 2014). Similar to E2, treatment with the selective GPER1 agonist G-1 increased PFKFB3 expression in a concentrationdependent manner (Fig. 5B). When taken together, the observations that treatment with GPER1 siRNA reduced E2-mediated HUVEC migration, tube-like structure formation, and PFKFB3 expression support the notion that $\mathrm{PFKFB} 3$ is required for estrogen-mediated EC migration through GPER1 signaling.

Several studies provide evidence for E2 effects in the control of energy balance in different cells and tissues (MauvaisJarvis et al., 2013; Della Torre et al., 2016). For instance, E2 is known to foster glucose uptake and utilization in several cancer cells (Sun et al., 2014). However, to the best of our knowledge, this is the first report linking hormonal effects to glycolysis activation in ECs with a special focus on the role of PFKFB3 in this process.

In conclusion, the present study showed that GPER1 is involved in E2-mediated angiogenesis. We also add knowledge to the mechanisms involved in E2-mediated angiogenesis by demonstrating that the glycolytic activator PFKFB3 is a downstream effector of E2 action in this process. These findings may have implications in angiogenesis occurring in ischemic or hypoxic tissues.

\section{Acknowledgments}

The authors are grateful to Dr. Marianela Vara Messler for assistance in preparing the endothelial cell cultures.

\section{Authorship Contributions}

Participated in research design: Bolego, Trevisi.

Conducted experiments: Trenti, Tedesco, Boscaro, Ferri. Performed data analysis: Trenti, Cignarella, Bolego.

Wrote or contributed to the writing of the manuscript: Cignarella, Trevisi, Bolego.

\section{References}

Abu-Taha M, Rius C, Hermenegildo C, Noguera I, Cerda-Nicolas JM, Issekutz AC Jose PJ, Cortijo J, Morcillo EJ, and Sanz MJ (2009) Menopause and ovariectomy cause a low grade of systemic inflammation that may be prevented by chronic treatment with low doses of estrogen or losartan. J Immunol 183:1393-1402.

Almeida A, Bolaños JP, and Moncada S (2010) E3 ubiquitin ligase APC/C-Cdh1 accounts for the Warburg effect by linking glycolysis to cell proliferation. Proc Natl Acad Sci USA 107:738-741.

Arnal JF, Fontaine C, Billon-Galés A, Favre J, Laurell H, Lenfant F, and Gourdy P (2010) Estrogen receptors and endothelium. Arterioscler Thromb Vasc Biol 30: 1506-1512

Billon-Galés A, Fontaine C, Douin-Echinard V, Delpy L, Berges H, Calippe B, Lenfant F, Laurell H, Guéry JC, Gourdy P, et al. (2009) Endothelial estrogen receptor- $\alpha$ plays a crucial role in the atheroprotective action of $17 \beta$-estradiol in low-density lipoprotein receptor-deficient mice. Circulation 120:2567-2576.

Bolego C, Buccellati C, Radaelli T, Cetin I, Puglisi L, Folco G, and Sala A (2006) eNOS, COX-2, and prostacyclin production are impaired in endothelial cells from diabetics. Biochem Biophys Res Commun 339:188-190.

Bolego C, Cignarella A, Staels B, and Chinetti-Gbaguidi G (2013) Macrophage function and polarization in cardiovascular disease: a role of estrogen signaling? Arterioscler Thromb Vasc Biol 33:1127-1134.

Bolego C, Rossoni G, Fadini GP, Vegeto E, Pinna C, Albiero M, Boscaro E, Agostini C, Avogaro A, Gaion RM, et al. (2010) Selective estrogen receptor- $\alpha$ agonist provides widespread heart and vascular protection with enhanced endothelial progenitor cell mobilization in the absence of uterotrophic action. FASEB J 24:2262-2272.

Carpentier G, Martinelli M, Courty J, and Cascone I (2012) Angiogenesis Analyzer for ImageJ, in Proceedings of the 4th ImageJ User and Developer Conference; 2012 October 24-26; Mondorf-les-Bains, Luxembourg, pp 198-201.

Chesney J, Mitchell R, Benigni F, Bacher M, Spiegel L, Al-Abed Y, Han JH, Metz C, and Bucala R (1999) An inducible gene product for 6-phosphofructo-2-kinase with an AU-rich instability element: role in tumor cell glycolysis and the Warburg effect. Proc Natl Acad Sci USA 96:3047-3052.

Conter RL and Longmire WP, Jr (1988) Recurrent hepatic hemangiomas. Possible association with estrogen therapy. Ann Surg 207:115-119.

Cordero-Espinoza L and Hagen T (2013) Increased concentrations of fructose 2,6bisphosphate contribute to the Warburg effect in phosphatase and tensin homolog (PTEN)-deficient cells. J Biol Chem 288:36020-36028.

Culic O, Gruwel ML, and Schrader J (1997) Energy turnover of vascular endothelial cells. Am J Physiol 273:C205-C213.

Daher IN and Yeh ET (2008) Vascular complications of selected cancer therapies. Nat Clin Pract Cardiovasc Med 5:797-805.

De Bock K, Georgiadou M, Schoors S, Kuchnio A, Wong BW, Cantelmo AR, Quaegebeur A, Ghesquière B, Cauwenberghs S, Eelen G, et al. (2013) Role of PFKFB3-driven glycolysis in vessel sprouting. Cell 154:651-663.

Della Torre S, Mitro N, Fontana R, Gomaraschi M, Favari E, Recordati C, Lolli F, Quagliarini F, Meda C, Ohlsson C, et al. (2016) An essential role for liver ER $\alpha$ in coupling hepatic metabolism to the reproductive cycle. Cell Reports 15:360-371.

Fadini GP, de Kreutzenberg S, Albiero M, Coracina A, Pagnin E, Baesso I, Cignarella A, Bolego C, Plebani M, Nardelli GB, et al. (2008) Gender differences in endothelial progenitor cells and cardiovascular risk profile: the role of female estrogens. Arterioscler Thromb Vasc Biol 28:997-1004.

Favre J, Gao J, Henry JP, Remy-Jouet I, Fourquaux I, Billon-Gales A, Thuillez C, Arnal JF, Lenfant F, and Richard V (2010) Endothelial estrogen receptor $\alpha$ plays an essential role in the coronary and myocardial protective effects of estradiol in ischemia/reperfusion. Arterioscler Thromb Vasc Biol 30:2562-2567.

Ge X, Lyu P, Cao Z, Li J, Guo G, Xia W, and Gu Y (2015) Overexpression of miR-206 suppresses glycolysis, proliferation and migration in breast cancer cells via PFKFB3 targeting. Biochem Biophys Res Commun 463:1115-1121.

Geraldes P, Sirois MG, Bernatchez PN, and Tanguay JF (2002) Estrogen regulation of endothelial and smooth muscle cell migration and proliferation: role of p38 and p42/44 mitogen-activated protein kinase. Arterioscler Thromb Vasc Biol 22: $1585-1590$

Gopal S, Garibaldi S, Goglia L, Polak K, Palla G, Spina S, Genazzani AR, Genazzani $\mathrm{AD}$, and Simoncini T (2012) Estrogen regulates endothelial migration via plasminogen activator inhibitor (PAI-1). Mol Hum Reprod 18:410-416.

Goveia J, Stapor P, and Carmeliet P (2014) Principles of targeting endothelial cell metabolism to treat angiogenesis and endothelial cell dysfunction in disease. EMBO Mol Med 6:1105-1120.

Guidolin D, Vacca A, Nussdorfer GG, and Ribatti D (2004) A new image analysis method based on topological and fractal parameters to evaluate the angiostatic 
activity of docetaxel by using the Matrigel assay in vitro. Microvasc Res 67: 117-124.

Haran EF, Maretzek AF, Goldberg I, Horowitz A, and Degani H (1994) Tamoxifen enhances cell death in implanted MCF7 breast cancer by inhibiting endothelium growth. Cancer Res 54:5511-5514.

Hardman MJ and Ashcroft GS (2008) Estrogen, not intrinsic aging, is the major regulator of delayed human wound healing in the elderly. Genome Biol 9:R80.

Harris HA, Katzenellenbogen JA, and Katzenellenbogen BS (2002) Characterization of the biological roles of the estrogen receptors, $\mathrm{ER} \alpha$ and $\mathrm{ER} \beta$, in estrogen target tissues in vivo through the use of an $\mathrm{ER} \alpha$-selective ligand. Endocrinology 143: $4172-4177$.

Holm A, Grände PO, Ludueña RF, Olde B, Prasad V, Leeb-Lundberg LM, and Nilsson BO (2012) The G protein-coupled oestrogen receptor 1 agonist G-1 disrupts endothelial cell microtubule structure in a receptor-independent manner. $M o l$ Cell Biochem 366:239-249.

Holm P, Andersen HL, Andersen MR, Erhardtsen E, and Stender S (1999) The direct antiatherogenic effect of estrogen is present, absent, or reversed, depending on the state of the arterial endothelium. A time course study in cholesterol-clamped rabbits. Circulation 100:1727-1733.

Horak ER, Leek R, Klenk N, LeJeune S, Smith K, Stuart N, Greenall M, Stepniewska K, and Harris AL (1992) Angiogenesis, assessed by platelet/endothelial cell adhesion molecule antibodies, as indicator of node metastases and survival in breast cancer. Lancet 340:1120-1124.

Imbert-Fernandez Y, Clem BF, O’Neal J, Kerr DA, Spaulding R, Lanceta L, Clem AL, Telang S, and Chesney J (2014) Estradiol stimulates glucose metabolism via 6-phosphofructo-2-kinase (PFKFB3). J Biol Chem 289:9440-9448.

Iwakura A, Shastry S, Luedemann C, Hamada H, Kawamoto A, Kishore R, Zhu Y, Qin G, Silver M, Thorne T, et al. (2006) Estradiol enhances recovery after myocardial infarction by augmenting incorporation of bone marrow-derived endothelial progenitor cells into sites of ischemia-induced neovascularization via endothelial nitric oxide synthase-mediated activation of matrix metalloproteinase-9. Circulation 113:1605-1614.

Johns A, Freay AD, Fraser W, Korach KS, and Rubanyi GM (1996) Disruption of estrogen receptor gene prevents 17 beta estradiol-induced angiogenesis in transgenic mice. Endocrinology 137:4511-4513.

Lappano R, Rigiracciolo D, De Marco P, Avino S, Cappello AR, Rosano C, Maggiolini M, and De Francesco EM (2016) Recent advances on the role of G protein-coupled receptors in hypoxia-mediated signaling. AAPS J 18:305-310.

Laschke MW and Menger MD (2012) Anti-angiogenic treatment strategies for the therapy of endometriosis. Hum Reprod Update 18:682-702.

Losordo DW and Isner JM (2001) Estrogen and angiogenesis: a review. Arterioscler Thromb Vasc Biol 21:6-12.

Maggi A, Cignarella A, Brusadelli A, Bolego C, Pinna C, and Puglisi L (2003) Diabetes undermines estrogen control of inducible nitric oxide synthase function in rat aortic smooth muscle cells through overexpression of estrogen receptor- $\beta$. Circulation 108:211-217.

Mauvais-Jarvis F, Clegg DJ, and Hevener AL (2013) The role of estrogens in control of energy balance and glucose homeostasis. Endocr Rev 34:309-338.

Meyer MR, Fredette NC, Howard TA, Hu C, Ramesh C, Daniel C, Amann K, Arterburn JB, Barton M, and Prossnitz ER (2014) G protein-coupled estrogen receptor protects from atherosclerosis. Sci Rep 4:7564.

Morales DE, McGowan KA, Grant DS, Maheshwari S, Bhartiya D, Cid MC, Kleinman HK, and Schnaper HW (1995) Estrogen promotes angiogenic activity in human umbilical vein endothelial cells in vitro and in a murine model. Circulation 91: $755-763$.

Murata T, Dietrich HH, Xiang C, and Dacey RG, Jr (2013) G protein-coupled estrogen receptor agonist improves cerebral microvascular function after hypoxia/reoxygenation injury in male and female rats. Stroke 44:779-785.

Nasu K, Takai N, Nishida M, and Narahara H (2008) Tumorigenic effects of tamoxifen on the female genital tract. Clin Med Pathol 1:17-34.

Obach M, Navarro-Sabaté A, Caro J, Kong X, Duran J, Gómez M, Perales JC, Ventura F, Rosa JL, and Bartrons R (2004) 6-Phosphofructo-2-kinase ( $p f k f b 3$ ) gene promoter contains hypoxia-inducible factor-1 binding sites necessary for transactivation in response to hypoxia. J Biol Chem 279:53562-53570.

Otto C, Fuchs I, Kauselmann G, Kern H, Zevnik B, Andreasen P, Schwarz G, Altmann H, Klewer M, Schoor M, et al. (2009) GPR30 does not mediate estrogenic responses in reproductive organs in mice. Biol Reprod 80:34-41.

Pare G, Krust A, Karas RH, Dupont S, Aronovitz M, Chambon P, and Mendelsohn ME (2002) Estrogen receptor- $\alpha$ mediates the protective effects of estrogen against vascular injury. Circ Res 90:1087-1092.

Patel VH, Chen J, Ramanjaneya M, Karteris E, Zachariades E, Thomas P, Been M, and Randeva HS (2010) G-protein coupled estrogen receptor 1 expression in rat and human heart: protective role during ischaemic stress. Int $J$ Mol Med 26: 193-199.

Prossnitz ER and Arterburn JB (2015) International Union of Basic and Clinical Pharmacology. XCVII. G Protein-coupled estrogen receptor and its pharmacologic modulators. Pharmacol Rev 67:505-540.

Prossnitz ER and Barton M (2014) Estrogen biology: new insights into GPER function and clinical opportunities. Mol Cell Endocrinol 389:71-83.

Revankar CM, Cimino DF, Sklar LA, Arterburn JB, and Prossnitz ER (2005) A transmembrane intracellular estrogen receptor mediates rapid cell signaling. Science 307:1625-1630.

Reynolds LP, Killilea SD, and Redmer DA (1992) Angiogenesis in the female reproductive system. FASEB $J$ 6:886-892.

Riera L, Obach M, Navarro-Sabaté A, Duran J, Perales JC, Viñals F, Rosa JL, Ventura F, and Bartrons R (2003) Regulation of ubiquitous 6-phosphofructo-2kinase by the ubiquitin-proteasome proteolytic pathway during myogenic $\mathrm{C} 2 \mathrm{C} 12$ cell differentiation. FEBS Lett 550:23-29.

Rubanyi GM, Johns A, and Kauser K (2002) Effect of estrogen on endothelial function and angiogenesis. Vascul Pharmacol 38:89-98.

Sanchez AM, Flamini MI, Zullino S, Gopal S, Genazzani AR, and Simoncini T (2011) Estrogen receptor- $\alpha$ promotes endothelial cell motility through focal adhesion kinase. Mol Hum Reprod 17:219-226.

Schoors S, De Bock K, Cantelmo AR, Georgiadou M, Ghesquière B, Cauwenberghs S, Kuchnio A, Wong BW, Quaegebeur A, Goveia J, et al. (2014) Partial and transient reduction of glycolysis by PFKFB3 blockade reduces pathological angiogenesis. Cell Metab 19:37-48.

Simons M, Alitalo K, Annex BH, Augustin HG, Beam C, Berk BC, Byzova T, Carmeliet P, Chilian W, Cooke JP, et al.; American Heart Association Council on Basic Cardiovascular Sciences and Council on Cardiovascular Surgery and Anesthesia (2015) State-of-the-art methods for evaluation of angiogenesis and tissue vascularization: a scientific statement from the American Heart Association. Circ Res 116:e99-e132.

Spyridopoulos I, Sullivan AB, Kearney M, Isner JM, and Losordo DW (1997) Estrogen-receptor-mediated inhibition of human endothelial cell apoptosis. Estradiol as a survival factor. Circulation 95:1505-1514.

Sun Y, Gu X, Zhang E, Park MA, Pereira AM, Wang S, Morrison T, Li C, Blenis J, Gerbaudo VH, et al. (2014) Estradiol promotes pentose phosphate pathway addiction and cell survival via reactivation of Akt in mTORC1 hyperactive cells. Cell Death Dis 5:e1231.

Tawakol A, Singh P, Mojena M, Pimentel-Santillana M, Emami H, MacNabb M, Rudd JH, Narula J, Enriquez JA, Través PG, et al. (2015) HIF-1 $\alpha$ and PFKFB3 mediate a tight relationship between pro-inflammatory activation and anaerobic metabolism in atherosclerotic macrophages. Arterioscler Thromb Vasc Biol 35: 1463-1471.

Thomas P, Pang Y, Filardo EJ, and Dong J (2005) Identity of an estrogen membrane receptor coupled to a $\mathrm{G}$ protein in human breast cancer cells. Endocrinology 146: 624-632.

Toutain CE, Filipe C, Billon A, Fontaine C, Brouchet L, Guéry JC, Gourdy P, Arnal $\mathrm{JF}$, and Lenfant $\mathrm{F}$ (2009) Estrogen receptor $\alpha$ expression in both endothelium and hematopoietic cells is required for the accelerative effect of estradiol on reendothelialization. Arterioscler Thromb Vasc Biol 29:1543-1550.

Treps L, Conradi LC, Harjes U, and Carmeliet P (2016) Manipulating angiogenesis by targeting endothelial metabolism: hitting the engine rather than the drivers-a new perspective? Pharmacol Rev 68:872-887.

Verdegem D, Moens S, Stapor P, and Carmeliet P (2014) Endothelial cell metabolism: parallels and divergences with cancer cell metabolism. Cancer Metab 2:19.

Windahl SH, Andersson N, Chagin AS, Mårtensson UE, Carlsten H, Olde B, Swanson C, Movérare-Skrtic S, Sävendahl L, Lagerquist MK, et al. (2009) The role of the G protein-coupled receptor GPR30 in the effects of estrogen in ovariectomized mice. Am J Physiol Endocrinol Metab 296:E490-E496.

Xu Y, An X, Guo X, Habtetsion TG, Wang Y, Xu X, Kandala S, Li Q, Li H, Zhang C, et al. (2014) Endothelial PFKFB3 plays a critical role in angiogenesis. Arterioscler Thromb Vasc Biol 34:1231-1239.

Yalcin A, Clem BF, Simmons A, Lane A, Nelson K, Clem AL, Brock E, Siow D, Wattenberg B, Telang S, et al. (2009) Nuclear targeting of 6-phosphofructo-2 kinase (PFKFB3) increases proliferation via cyclin-dependent kinases. J Biol Chem 284:24223-24232.

Address correspondence to: Dr. Andrea Cignarella, Department of Pharmaceutical and Pharmacological Sciences, Pharmacology Building, Largo E. Meneghetti 2, I-35131 Padova, Italy. E-mail: andrea.cignarella@unipd.it 